\title{
Faktor-Faktor yang Berhubungan dengan Partisipasi Ibu dalam Penimbangan Balita
}

\section{Factors Associatied with Mother Participation of Weighing Toddler}

\author{
Nur Sefa Arief Hermawan ${ }^{(1)}$, Leny Anggraini( ${ }^{(2)}$, Rohman Nurhadi ${ }^{(3)}$ \\ (1)Program Studi Kesehatan Masyarakat, Universitas Mitra Indonesia, Indonesia \\ (2)Program Studi D3 ATRO Patriot Bangsa Husada, Indonesia \\ ${ }^{(3)}$ Puskesmas Srimulyo Suoh Lampung Barat, Indonesia
}

\begin{abstract}
Korespondensi Penulis: Nur Sefa Arief Hermawan, Program Studi Kesehatan Masyarakat, Universitas Mitra Indonesia

Email: sefa@umitra.ac.id
\end{abstract}

\begin{abstract}
ABSTRAK
Cakupan penimbangan balita di Kabupaten Lampung Barat tahun 2016 belum memenuhi target. Dari 11 Puskesmas di Kabupaten Lampung Barat, UPT Puskesmas Rawat Inap Srimulyo merupakan puskesmas dengan cakupan penimbangan balita belum optimal karena pencapaian cakupan penimbangan balita menurun, dari 62,8\% pada tahun 2015 menjadi 52,5\% pada tahun 2016, angka ini masih rendah artinya belum memenuhi target pencapaian sebesar $75 \%$. Tujuan penelitian ini adalah untuk mengetahui faktorfaktor yang berhubungan dengan partisipasi ibu dalam penimbangan balita di wilayah kerja UPT Puskesmas Rawat Inap Srimulyo Suoh Lampung Barat Tahun 2017. Dalam hal ini, peneliti melihat variabel pengetahuan dan sikap ibu. Jenis penelitian yang digunakan kuantitatif, dengan pendekatan Cross Sectional. Populasi dalam penelitian ini adalah seluruh ibu yang mempunyai balita yang berada di wilayah kerja UPT Puskesmas Rawat Inap Srimulyo Suoh Lampung Barat yang berjumlah 54 responden. Dalam penelitian ini teknik sampling yang digunakan menggunakan total populasi. Hasil dalam penelitian diketahui p value untuk variabel pengetahuan $\mathrm{p}$ value $=0,04$ dan sikap $\mathrm{p}$ value $=0,025$ sehingga $\mathrm{p}$ value $<0,05$ yang artinya terdapat hubungan antara pengetahuan dan sikap dengan partisipasi ibu dalam penimbangan balita di wilayah kerja UPT Puskesmas Rawat Inap Srimulyo Suoh Lampung Barat. Saran bagi ibu balita agar dapat terus meningkatkan partisipasi atau keaktifan dalam mengikuti kegiatan posyandu baik dengan bertanya kepada petugas kesehatan tentang penimbangan balita dan pemanfaatan pelayanan kesehatan dengan sebaik-baiknya.
\end{abstract}

Kata Kunci : Partisipasi, Ibu, Penimbangan Balita

\section{ABSTRACT}

The coverage of weighing toddlers in West Lampung Regency in 2016 has not met the target. From the 11 of health center in West Lampung Regency, The Srimulyo Suoh health center (Puskesmas) is a health center with underfive weighing coverage because the achievement of underfive weighing coverage has decreased, from $62.8 \%$ in 2015 to $52.5 \%$ in 2016, this figure is still low means has not met the achievement target of $75 \%$. The purpose of this study was to determine the relationship between knowledge and attitudes with maternal participation in weighing toddlers in the Working Area of the Puskesmas Srimulyo Suoh in West Lampung 2017. The purpose of this study was to determine the factors related to maternal participation in weighing toddlers in the working area of The Srimulyo Suoh health center in West Lampung in 2017. In this case, the researchers looked at the variable knowledge and attitudes of mothers. This type of research is quantitative, with the cross sectional approach. The population in this study were all mothers who had children under five who were in the Working Area of the Puskesmas Srimulyo Suoh West Lampung amounting to 54 respondents. In this study the sampling technique used uses the total population. The results in the study found that $p$ value for the knowledge variable $p$ value $=0.04$ and attitude $p$ value $=0.025$ so that $p$ value $<0.05$, which means there is a relationship between knowledge and attitudes with maternal participation in weighing toddlers in the Puskesmas Srimulyo Suoh West Lampung. Suggestions for mothers of children under five so that they can continue to improve their activity in participating in good posyandu activities by asking health workers about weighing toddlers and using health services as well as possible. 


\section{PENDAHULUAN}

Berdasarkan penimbangan balita di posyandu, ditemukan kasus gizi buruk sebanyak 26.518 balita. Kasus gizi buruk yang dimaksud ditentukan berdasarkan perhitungan berat badan menurut tinggi badan balita $\mathrm{Z}$ score kurang dari -3 standar deviasi (balita sangat kurus). Sedangkan menurut hasil Riskesdas tahun 2013 prevalensi gizi sangat kurus pada balita di Indonesia sebesar 5,3\%. Jika diestimasikan terhadap jumlah sasaran balita terdaftar di posyandu yang melapor (21.436.940) maka perkiraan jumlah balita gizi buruk (sangat kurus) sebanyak 1,1 juta jiwa (Kemenkes RI, 2015).

Pemantauan pertumbuhan balita sangat penting dilakukan untuk mengetahui adanya gangguan pertumbuhan secara dini. Untuk mengetahui pertumbuhan tersebut, penimbangan balita setiap bulan sangat diperlukan. Penimbangan balita dapat dilakukan diberbagai tempat seperti Posyandu, Polindes, Puskesmas atau sarana pelayanan kesehatan yang lain. Informasi tentang pemantauan pertumbuhan anak diperoleh dari frekuensi penimbangan anak umur 6-59 bulan selama enam bulan terakhir. Idealnya dalam enam bulan anak balita ditimbang minimal enam kali. Frekuensi penimbangan lebih dari empat kali sedikit menurun pada tahun 2013 (44,6\%) dibanding tahun 2007 (45,4\%). Anak balita umur 6-59 bulan yang tidak pernah ditimbang dalam enam bulan terakhir meningkat dari $\quad 25,5 \% \quad$ (2007) menjadi $34,3 \% \quad$ (2013) (Riskesdas, 2013).

Menteri Perencanaan Pembangunan Nasional tahun 2014 menyatakan salah satu sasaran Rencana Pembangunan Jangka Menengah Nasional (RPJMN) 2015-2019 adalah menurunnya prevalensi masalah kekurangan gizi pada anak balita dari $19,6 \%$ pada tahun 2013 menjadi $17,0 \%$ pada target $2015-2019$. Strategi utama untuk menurunkan prevalensi masalah gizi adalah meningkatkan kegiatan pencegahan melalui pemantauan pertumbuhan anak di Posyandu (Kemenkes RI, 2015).

Dalam memantau pertumbuhan balita indikator yang digunakan adalah Cakupan Balita Ditimbang (D/S) dan Balita yang Naik Berat Badan (N/D). Cakupan D/S pada tahun (2012) sebesar $74,51 \%$ target $75 \%$, pada tahun (2013) sebesar 72,60\% target 75\%, tahun (2014) sebesar $80 \%$ target $75 \%$ dan, tahun (2015) sebesar $74,70 \%$ dari target $75 \%$ menunjukan kecenderungan berfluktuatif, sedangkan N/D juga menunjukan kecenderungan berfluktuatif dari tahun (2012) sebesar $83,32 \%$ target 75\%, tahun (2013) sebesar $81,53 \%$ target $75 \%$, tahun (2014) sebesar $63,5 \%$ target 75\% dan, tahun (2015) 64\% dari target 75\% (Profil Dinas Kesehatan Provinsi Lampung, 2015).

Cakupan balita ditimbang (D/S) di Provinsi Lampung tahun 2015 sebesar 74,70\%, dimana angka ini masih dibawah target (75\%). Angka ini menggambarkan bahwa partisipasi dari masyarakat untuk datang ke Posyandu belum memenuhi target. Sedangkan Cakupan balita ditimbang yang naik berat badannya (N/D) di Provinsi Lampung tahun 2015 sebesar $64 \%$ dimana target yang diharapkan (>75\%). Angka ini menggambarkan bahwa kinerja dari petugas kesehatan dalam program perbaikan gizi baik dari lintas program maupun lintas sektor belum optimal. Cakupan balita ditimbang (D/S) dengan presentase tertinggi berada di Kabupaten Lampung Utara sebesar 99,93\%. Sedangkan Kabupaten dengan cakupan balita ditimbang (D/S) terendah berada di Kabupaten Lampung Barat sebesar 67,05\%, Kabupaten Way Kanan 68,7\% dan di ikuti Kota Metro dengan persentase sebesar 70,28\%, dan Kabupaten Lampung Barat masuk pada urutan pertama dalam program perbaikan gizi (Profil Dinas Kesehatan Provinsi Lampung, 2015).

Cakupan penimbangan balita di Kabupaten Lampung Barat tahun 2016 belum memenuhi target. Hal ini dapat dilihat dari hasil pencapaian cakupan penimbangan balita sebesar 52,5\% dari yang ditargetkan 75\%. Dari 11 Puskesmas di Kabupaten Lampung Barat, UPT Puskesmas Rawat Inap Srimulyo merupakan Puskesmas dengan cakupan penimbangan balita belum optimal karena pencapaian cakupan penimbangan balita menurun, dari $62,8 \%$ pada tahun 2015 menurun menjadi 52,5\% pada tahun 2016, angka ini masih rendah artinya belum memenuhi target pencapaian sebesar 75\% (Dinkes Kabupaten Lampung Barat, 2016).

Salah satu faktor yang mendorong penurunan pemantauan pertumbuhan balita 
di Puskesmas Srimulyo Suoh adalah karena ketidaktahuan ibu terhadap manfaat penimbangan balita Di Posyandu, baik pengetahuan atau sikap ibu bahkan partisipasi ibu dalam melakukan penimbangan balita masih rendah. Padahal penimbangan terhadap balita yang dilakukan di Puskesmas merupakan upaya partisipasi masyarakat memantau pertumbuhan dan perkembanganya (Profil Puskesmas Rawat Inap Srimulyo Suoh Kabupaten Lampung Barat, 2017).

Dampak yang dialami balita apabila tidak aktif dalam kegiatan penimbangan di Posyandu antara lain tidak mendapat penyuluhan kesehatan, tidak mendapat vitamin A, ibu balita tidak mengetahui pertumbuhan dan perkembangan berat badan balita, ibu balita tidak mendapatkan pemberian dan penyuluhan tentang makanan tambahan (PMT). Hal tersebut memicu munculnya permasalahan gizi, baik gizi sedang, gizi kurang, maupun gizi buruk pada balita yang akan berdampak sangat fatal yaitu dapat menyebabkan kematian. Penimbangan balita menjadi pemantauan dasar yang penting bagi anak balita yang paling awal dalam memantau pertumbuhan dan perkembangannya (Elva dkk, 2016). Berdasarkan uraian tersebut di atas maka peneliti tertarik melakukan penelitian tentang "Determinan Partisipasi Ibu Dalam Penimbangan Balita Di Wilayah Kerja UPT Puskesmas Rawat Inap Srimulyo Suoh Lampung Barat Tahun 2017".

\section{SUBYEK DAN METODE}

Jenis penelitian yang digunakan dalam penelitian ini adalah kuantitatif dengan desain penelitian survey analitik menggunakan pendekatan cross sectional yaitu penelitian yang dilakukan pada satu saat atau satu periode tertentu dan pengamatan obyek studi hanya dilakukan sekali (Notoatmodjo, 2010). Populasi dalam penelitian ini adalah seluruh ibu yang mempunyai balita yang berada di Wilayah Kerja UPT Puskesmas Rawat Inap Srimulyo Suoh Lampung Barat Tahun 2017 yang berjumlah 54 ibu balita.

Sampel dalam penelitian ini berjumlah 54 ibu balita. Kriteria Sampel: 1) Ibu balita yang memiliki balita usia 6-59 bulan, 2) Bersedia menjadi ibu balita tanpa paksaan, 3) Ibu dan Balita dalam keadaan sehat. Dalam penelitian ini teknik sampling yang digunakan adalah total populasi. Pengumpulan data menggunakan data primer yaitu data yang diperoleh langsung dari ibu balita menggunakan instrument tentang pengetahuan dan sikap ibu balita tentang penimbangan balita. Data Sekunder diperoleh dari UPT Puskesmas Rawat Inap Srimulyo Suoh Lampung Barat yang berupa data penimbangan balita dan lembar partisipasi.

\section{HASIL}

Berdasarkan Tabel 1, diketahui bahwa Di Wilayah Kerja UPT Puskesmas Rawat Inap Srimulyo Suoh Lampung Barat Tahun 2017, ibu balita yang mempunyai pengetahuan baik berjumlah $22 \mathrm{ibu}$, dimana partisipasi ibu dalam penimbangan balita yang baik berjumlah 15 ibu $(68,2 \%)$ dan yang buruk berjumlah 7 ibu $(31,8 \%)$, sedangkan ibu balita yang mempunyai pengetahuan kurang baik berjumlah $32 \mathrm{ibu}$, dimana partisipasi ibu dalam penimbangan balita baik berjumlah 8 ibu $(25,0 \%)$ dan yang kurang baik berjumlah $24 \mathrm{ibu}(75,0 \%)$.

Berdasarkan analisa data, diketahui bahwa $\mathrm{p}$ value $=0,004$ atau $\mathrm{p}$ value $<0,05$ yang artinya terdapat hubungan antara pengetahuan dengan partisipasi ibu balita dalam penimbangan balita Di Wilayah Kerja UPT Puskesmas Rawat Inap Srimulyo Suoh Lampung Barat Tahun 2017

Tabel 1. Analisis Hubungan Antara Pengetahuan dengan Partisipasi Ibu Balita

\begin{tabular}{|c|c|c|c|c|c|c|c|c|}
\hline \multirow{3}{*}{ Pengetahuan } & \multicolumn{4}{|c|}{ Partisipasi Ibu Balita } & \multirow{2}{*}{\multicolumn{2}{|c|}{ Total }} & \multirow{3}{*}{ P value } & \multirow{3}{*}{ OR (Cl 95\%) } \\
\hline & \multicolumn{2}{|c|}{ Baik } & \multicolumn{2}{|c|}{ Buruk } & & & & \\
\hline & $\mathbf{n}$ & $\%$ & $\mathbf{n}$ & $\%$ & $\mathbf{n}$ & $\%$ & & \\
\hline Baik & 15 & 68,2 & 7 & 31,8 & 22 & 100,0 & 0,004 & 6,429 \\
\hline Kurang Baik & 8 & 25,0 & 24 & 75,0 & 32 & 100,0 & & $(1,93-11,38)$ \\
\hline
\end{tabular}


Tabel 2. Analisis Hubungan Antara Sikap dengan Partisipasi Ibu Balita

\begin{tabular}{lcccccccc}
\hline \multirow{3}{*}{ Sikap } & \multicolumn{4}{c}{ Partisipasi Ibu Balita } & \multirow{2}{*}{ Total } & \multirow{2}{*}{ P value } & \multirow{2}{*}{ OR (Cl 95\%) } \\
\cline { 2 - 6 } & \multicolumn{2}{c}{ Baik } & \multicolumn{2}{c}{ Buruk } & & & \\
\cline { 2 - 6 } & $\mathbf{n}$ & $\mathbf{\%}$ & $\mathbf{n}$ & $\mathbf{\%}$ & $\mathbf{n}$ & $\mathbf{\%}$ & & \\
\hline Positif & 12 & 66,7 & 6 & 33,3 & 18 & 100,0 & 0,025 & 2,20 \\
Negatif & 11 & 30,6 & 25 & 69,4 & 36 & 100,0 & & $(1,62-7,36)$ \\
\hline
\end{tabular}

dengan niali OR sebesar 6,429 yang artinya ibu balita dengan pengetahuan baik mempunyai peluang 6 kali lebih besar untuk berpartisipasi dalam kegiatan penimbangan balita.

Berdasarkan Tabel 2, diketahui bahwa Di Wilayah Kerja UPT Puskesmas Rawat Inap Srimulyo Suoh Lampung Barat Tahun 2017, ibu balita yang mempunyai sikap positif berjumlah $18 \mathrm{ibu}$, dimana yang partisipasi ibu balita dalam penimbangan balita baik berjumlah $12 \mathrm{ibu}$ $(66,7 \%)$ dan yang kurang baik berjumlah $6 \mathrm{ibu}$ (33,3\%), sedangkan ibu balita yang mempunyai sikap negatif berjumlah $36 \mathrm{ibu}$, dimana partisipasi ibu dalam penimbangan balita baik berjumlah 11 ibu (30,6\%) dan yang buruk berjumlah $25 \mathrm{ibu}$ $(69,4 \%)$. Berdasarkan analisa data, diketahui bahwa $\mathrm{p}$ value $=0,025$ atau $\mathrm{p}$ value $<0,05$ yang artinya terdapat hubungan antara sikap dengan partisipasi ibu dalam penimbangan balita Di Wilayah Kerja UPT Puskesmas Rawat Inap Srimulyo Suoh Lampung Barat Tahun 2017 dengan nilai OR sebesar 2,20 yang artinya ibu balita yang mempunyai sikap positif mempunyai peluang 2 kali lebih besar untuk mengikuti penimbangan balita yang baik.

\section{DISKUSI}

Menurut (Notoadmojo, 2012), pengetahuan adalah hasil dari tahu, dan ini terjadi setelah orang melakukan pengindraan terhadap suatu objek tertentu. Pengindraan terjadi melalui pancaindra manusia, yakni indra penglihatan, pendengaran, penciuman, rasa dan raba. Dengan sendirinya pada waktu pengindraan sehingga menghasilkan pengetahuan tersebut sangat dipengaruhi oleh intensitas perhatian dan persepsi terhadap objek. Sebagian besar pengetahuan manusia diperoleh melalui mata dan telinga. Penimbangan bulanan balita adalah salah satu kegiatan yang harus dilaksanakan di setiap pelaksanaan Posyandu. Hasil penimbangan ini merupakan suatu indikator bagi ibu-ibu dalam mengetahui apakah anaknya ini sehat atau tidak, dan inipun dapat mempengaruhi perilaku ibuibu dalam penimbangan berikutnya (Depkes RI, 2013).

Peran serta petugas kesehatan dan masyarakat dalam penimbangan balita menjadi sangat penting dalam deteksi dini kasus gizi kurang dan gizi buruk. Dengan rajin menimbang balita, maka pertumbuhan balita dapat dipantau secara intensif. Sehingga bila berat badan anak tidak naik ataupun jika ditemukan penyakit akan dapat segera dilakukan upaya pemulihan dan pencegahan supaya tidak menjadi gizi kurang atau gizi buruk. Semakin cepat ditemukan, maka penanganan kasus gizi kurang atau gizi buruk akan semakin baik. Penanganan yang cepat dan tepat sesuai tata laksana kasus anak gizi buruk akan mengurangi risiko kematian sehingga angka kematian akibat gizi buruk dapat ditekan. Tindak lanjut dari hasil penimbangan selain penyuluhan juga pemberian makanan tambahan dan pemberian suplemen gizi. Gizi buruk dapat terjadi pada semua kelompok umur, tetapi yang perlu lebih diperhatikan yaitu pada kelompok bayi dan balita. Pada usia 0-2 tahun merupakan masa tumbuh kembang yang optimal (golden period) terutama untuk pertumbuhan janin sehingga bila terjadi gangguan pada masa ini tidak dapat dicukupi pada masa berikutnya dan akan berpengaruh negatif pada kualitas generasi penerus (Kemenkes RI, 2015).

Menurut penelitian Yuni dkk (2013) tentang hubungan pengetahuan dengan perilaku ibu dalam penimbangan balita Di Posyandu Anggrek Tulang Bawang Barat Tahun 2013, menyebutkan bahwa terdapat hubungan yang signifikan antara pengetahuan ibu dengan perilaku penimbangan balita dengan $\mathrm{p}$ value $=0,001$ atau $\mathrm{p}$ value $<$ 0,05 . Hasil penelitian ini sejalan dengan Yuni dkk (2013) dan teori menurut (Notoadmojo, 
2012) yang menyatakan bahwa semakin rendah pengetahuan ibu balita maka semakin buruk pertisipasi ibu dalam melakukan penimbangan balita, berdasarkan hasil penelitian yang peneliti lakukan, rata-rata ibu balita mempunyai pengetahuan yang kurang, hal ini dikarenakan kurangnya pendidikan kesehatan tentang pentingnya penimbangan balita, namun pada hasil penelitian yang peneliti lakukan bahwa ibu balita yang mempunyai pengetahuan baik berjumlah 22 ibu, dimana partisipasi ibu dalam penimbangan balita yang buruk berjumlah $7 \mathrm{ibu}(31,8 \%)$, hal ini dikarenakan faktor jarak, karena rata-rata jarak antara rumah ibu balita dengan Posyandu berkisar $\pm 7-10 \mathrm{~km}^{2}$, rendahnya pendidikan karena rata-rata pendidikan responden adalah sekolah dasar (SD) serta banyaknya pekerjaan ibu yang terlalu sibuk dengan pekerjaannya sebagai pedagang, yang mana responden mulai bekerja pukul 05.00 sampai dengan 18.00 WIB, sehingga banyak ibu balita tidak melakukan penimbangan, hasil penelitian ini sejalan dengan hasil penelitian yang dilakukan oleh Yuni dkk (2013) yang menyebutkan bahwa terdapat hubungan yang signifikan antara pengetahuan ibu dengan perilaku penimbangan balita.

Sikap merupakan reaksi atau respons yang masih tertutup dari seseorang terhadap suatu stimulus atau objek (Notoatmodjo, 2012). Sikap merupakan organisasi pendapat, keyakinan seseorang mengenai objek atau situasi yang relatif, yang disertai adanya perasaan tertentu, dan memberikan dasar pada orang tersebut untuk membuat respons atau berprilaku dalam cara tertentu yang dipilihnya. Menurut Waryana (2016) kegiatan pemantauan pertumbuhan anak dilaksanakan oleh ibu-ibu bersama dengan kader melalui kegiatan penimbangan rutin di Posyandu. Kegiatan bulanan di Posyandu merupakan kegiatan rutin yang bertujuan untuk: memantau pertumbuhan berat badan balita, memberikan konseling gizi, memberikan pelayanan gizi dan kesehatan dasar, dan untuk lebih meyakinkan ibu-ibu mengerti pentingnya hubungan makanan dengan kesehatan anak.

Penimbangan balita setiap bulan di Posyandu sangat bermanfaat untuk mengetahui apakah balita tumbuh sehat, untuk mengetahui dan mencegah gangguan pertumbuhan balita dan untuk mengetahui balita yang sakit, (demam/ batuk/diare). Bayi dengan berat badan selama dua tahun berturut-turut tidak naik, balita yang berat badannya BGM (Bawah Garis Merah) dan dicurigai Gizi buruk dapat segera dirujuk ke Puskesmas, untuk mengetahui kelengkapan imunisasi dan untuk mendapatkan penyuluhan gizi (Proverawati \& Rahmawati, 2012).

Berdasarkan hasil penelitian dan pembahasan diatas, maka menurut peneliti semakin negatif sikap ibu balita tentang partisipasi penimbangan balita maka semakin buruk ibu tidak melakukan penimbangan balita, sehingga berdampak pada pertumbuhan dan perkembangan balita. Kesimpulan dalam penelitian ini adalah pengetahuan sangat berkaitan dengan sikap, jika pengetahuan responden kurang maka sikap responden juga akan negatif, begitu juga dengan sebaliknya, berdasarkan hasil penelitian, dapat diketahui bahwa sebagian besar responden mempunyai pengetahuan yang kurang, dan sebagian besar responden juga mempunyai sikap yang negatif, dari dua masalah tersebut maka dapat mempengaruhi partisipasi ibu dalam melakukan penimbangan balita, sehingga akan berdampak pada pertumbuhan dan perkembangan balita, Namun didalam hasil penelitian diketahui bahwa ibu balita yang mempunyai sikap positif berjumlah $18 \mathrm{ibu}$, dimana yang partisipasi ibu balita dalam penimbangan balita yang kurang baik berjumlah $6 \mathrm{ibu}(33,3 \%)$, hal ini dikarenakan terdapatnya faktor lain seperti kurangnya pengetahuan tentang pentingnya penimbangan balita, status pekerjaan yang banyak menyita waktu, kurangnya dukungan keluarga karena masing-masing anggota keluarga sibuk dengan pekerjaan serta kegiatan sendiri, serta kurangnya informasi kesehatan yang didapatkan oleh ibu balita khususnya tentang pentingnya penimbangan balita setiap bulan.

\section{KESIMPULAN}

Berdasarkan hasil penelitian dan pembahasan diatas, maka kesimpulan dalam penelitian ini adalah terdapat hubungan antara pengetahuan dengan partisipasi ibu balita dalam penimbangan balita Di Wilayah Kerja UPT Puskesmas Rawat Inap Srimulyo Suoh Lampung Barat Tahun 2017 dengan nilai p value sebesar 0,004 . Terdapat hubungan antara sikap dengan partisipasi ibu dalam penimbangan balita Di 
161 Nur Sefa Arief Hermawan, Leny Anggraini, Rohman Nurhadi Faktor-Faktor yang Berhubungan dengan Partisipasi Ibu...

Wilayah Kerja UPT Puskesmas Rawat Inap Srimulyo Suoh Lampung Barat Tahun 2017 dengan $\mathrm{p}$ value sebesar 0,025. Berdasarkan hal tersebut, diharapkan agar ibu balita dapat meningkatkan keaktifan dalam mengikuti kegiatan Posyandu dengan cara bertanya kepada petugas kesehatan tentang penimbangan balita setiap dilakukannya penimbangan balita dan memanfaatkan pelayanan kesehatan dengan sebaik-baiknya dan bagi Puskesmas Rawat Inap Srimulyo Suoh Lampung Barat dapat meningkatkan pelayanan kesehatan dengan cara memberikan pendidikan kesehatan melalui penyuluhan kesehatan menggunakan media yang menarik, serta membuat kegiatan promosi kesehatan tentang pentingnya penimbangan balita seperti menyebarkan brosur, menempelkan beberapa spanduk atau banner tentang pentingnya kegiatan Posyandu pada balita.

\section{DAFTAR PUSTAKA}

Depkes RI. (2013). Peraturan Pembentukan Kader Dalam Lingkungan Masyarakat. Jakarta. RI

Dinkes Kabupaten Lampung Barat. (2016). Profil Cakupan Penimbangan Balita. Lampung Barat
Dinas Kesehatan Provinsi Lampung. (2015). Profil Dinas Kesehatan Provinsi Lampung. Lampung

Dinkes Kabupaten Lampung Barat. (2016). Cakupan Status Gizi Balita. Dinkes Lampung Barat

Elva. (2016). Perilaku Kesehatan Dalam Pembentukan Program Posyandu. Jakarta. Rineka Cipta

Kemenkes RI. (2015). Profil Kementerian Kesehatan Republik Indonesia Tahun 2015. Jakarta

Notoatmodjo, S. (2010). Metodologi Penelitian Kesehatan. Jakarta: Rineka Cipta

Notoatmodjo, S. (2012). Promosi Kesehatan dan Perilaku Kesehatan. Jakarta: Rineka Cipta

Profil Puskesmas Rawat Inap Srimulyo Suoh Kabupaten Lampung Barat, (2017). Cakupan Penimbangan Balita Dalam Status Gizi Balita. Suoh Lampung Barat

Proverawati, A dan Rahmawati, E. (2012). Perilaku Hidup Bersih dan Sehat (PHBS). Yogyakarta: Nuha Medika

Riskesdas. (2013). Profil Riset Kesehatan Dasar Tahun 2013. Jakarta

Waryana. (2016). Promosi Kesehatan Penyuluhan, dan Pemberdayaan Masyarakat. Yogyakarta: Nuha Medika

Yuni. (2013). Hubungan pengetahuan dengan perilaku ibu dalam penimbangan balita Di Posyandu Anggrek Tulang Bawang Barat Tahun 2013 